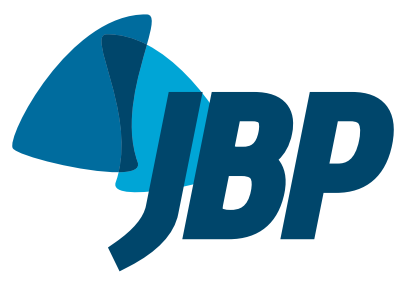

\title{
Effects of manual chest compression on expiratory flow bias during the positive end-expiratory pressure-zero end- expiratory pressure maneuver in patients on mechanical ventilation
}

\author{
Ana Carolina Otoni Oliveira ${ }^{1, a}$, Daiane Menezes Lorena ${ }^{1, b}$, \\ Lívia Corrêa Gomes ${ }^{2, c}$, Bianca Lorrane Reges Amaral ${ }^{2, d}$, Márcia Souza Volpe
}

1. Programa de Residência Integrada Multiprofissional em Saúde do Adulto, Universidade Federal do Triângulo Mineiro - UFTM - Uberaba (MG) Brasil.

2. Departamento de Fisioterapia Aplicada, Universidade Federal do Triângulo Mineiro - UFTM - Uberaba (MG) Brasil.

3. Departamento de Ciências do Movimento Humano, Universidade Federal de São Paulo - Unifesp Campus Baixada Santista, Santos (SP) Brasil.

a. (iD http://orcid.org/0000-0002-2752-6497

b. (D) http://orcid.org/0000-0002-4193-7946

c. (iD) http://orcid.org/0000-0001-7244-2973

d. (D) http://orcid.org/0000-0002-3794-3366

e. (D) http://orcid.org/0000-0003-1179-6254

Submitted: 23 February 2018. Accepted: 12 August 2018

Study carried out at the Hospital de Clínicas, Universidade Federal do Triângulo Mineiro - UFTM - Uberaba (MG) Brasil.

\begin{abstract}
Objective: To investigate the effects of manual chest compression (MCC) on the expiratory flow bias during the positive end-expiratory pressure-zero end-expiratory pressure (PEEP-ZEEP) airway clearance maneuver applied in patients on mechanical ventilation. The flow bias, which influences pulmonary secretion removal, is evaluated by the ratio and difference between the peak expiratory flow (PEF) and the peak inspiratory flow (PIF). Methods: This was a crossover randomized study involving 10 patients. The PEEP-ZEEP maneuver was applied at four time points, one without MCC and the other three with MCC, which were performed by three different respiratory therapists. Respiratory mechanics data were obtained with a specific monitor. Results: The PEEPZEEP maneuver without MCC was enough to exceed the threshold that is considered necessary to move secretion toward the glottis (PEF - PIF difference $>33 \mathrm{~L} / \mathrm{min}$ ): a mean PEF - PIF difference of $49.1 \pm 9.4 \mathrm{~L} / \mathrm{min}$ was achieved. The mean PEF/PIF ratio achieved was $3.3 \pm 0.7$. Using MCC with PEEP-ZEEP increased the mean PEF - PIF difference by $6.7 \pm 3.4 \mathrm{~L} / \mathrm{min}$. We found a moderate correlation between respiratory therapist hand grip strength and the flow bias generated with MCC. No adverse hemodynamic or respiratory effects were found. Conclusions: The PEEP-ZEEP maneuver, without MCC, resulted in an expiratory flow bias superior to that necessary to facilitate pulmonary secretion removal. Combining MCC with the PEEP-ZEEP maneuver increased the expiratory flow bias, which increases the potential of the maneuver to remove secretions.
\end{abstract}

Keywords: Physical therapy modalities; Critical care; Respiration, artificial; Bodily secretions.

\section{INTRODUCTION}

Patients undergoing mechanical ventilation show changes in the airway clearance mechanisms, those changes favoring the retention of pulmonary secretions. ${ }^{(1,2)}$ The accumulation of secretions causes an increase in airway resistance and partial or total airway obstruction, resulting in alveolar hypoventilation, atelectasis, hypoxemia, and increased work of breathing, as well as creating a favorable environment for the proliferation of bacteria and the development of pneumonia. ${ }^{(3,4)}$ All of those changes prolong the time to weaning from mechanical ventilation and worsen patient prognosis. ${ }^{(5)}$ In this context, respiratory therapy, applying manual techniques or using the mechanical ventilator itself, acts with the purpose of facilitating secretion removal and consequently improving the clinical course of critically ill patients. $(6,7)$

Since the 1980s, there have been studies showing that pulmonary secretion removal depends not only on high expiratory flows but also on the presence of an expiratory flow bias, that is, on PEF being higher than the peak inspiratory flow (PIF) generated in the airways. ${ }^{(8-10)}$ To date, four thresholds have been described for an expiratory flow bias to move secretion toward the glottis: PEF/PIF ratio > 1.1 ${ }^{(8,9)}$; PEF - PIF difference $>$ $17 \mathrm{~L} / \mathrm{min}^{(11)} ; \mathrm{PEF} / \mathrm{PIF}$ ratio > 4.3(12); and PEF - PIF difference $>33 \mathrm{~L} / \mathrm{min}$.(12) Of those four thresholds, the latter two have a greater potential for reflecting human conditions because they were discovered in an animal study, with the use of secretion from the animals themselves, and because the influence of gravity on secretion movement was taken into account in that study, given that the animals were kept in a semirecumbent position. (12) With regard to the choice between the threshold based on the PEF/PIF ratio and that based on PEF - PIF difference, Volpe et al.(11) showed that PEF - PIF difference has a stronger and more significant correlation with secretion movement than does the PEF/ PIF ratio. Therefore, using PEF - PIF difference as the

Correspondence to:

Márcia Souza Volpe. Departamento de Ciências do Movimento Humano, Universidade Federal de São Paulo, Unifesp، Rua Silva Jardim, 136, CEP 11015-020,

Santos, SP, Brasil.

Tel.: 5534 99183-2000. E-mail: marciasvolpe@gmail.com

Financial support: None. 
target threshold for an expiratory flow bias to remove secretions seems to be more appropriate.

Among the secretion removal techniques with great potential to generate an expiratory flow bias are the positive end-expiratory pressure-zero end-expiratory pressure (PEEP-ZEEP) maneuver and manual chest compression (MCC), which can be combined. However, there have been few studies investigating PEEP-ZEEP, and little is known about the ventilation pattern and flow bias generated during it. Herbst-Rodrigues et al. ${ }^{(13)}$ demonstrated that combining PEEP-ZEEP with MCC is a safe technique and that it resulted in increased $P E F$ in myocardial revascularization patients during the immediate postoperative period. Santos et al. ${ }^{(14)}$ compared PEEP-ZEEP vs. MCC, whereas Lobo et al. ${ }^{(15)}$ compared PEEP-ZEEP plus MCC vs. manual hyperinflation, and neither group found PEEP-ZEEP to be superior in terms of improvement in lung compliance ${ }^{(14)}$ or in terms of the quantity of secretions removed. ${ }^{(15)}$ Except for the study by Herbst-Rodrigues et al., ${ }^{(13)}$ those studies did not investigate the airflows achieved during the maneuver, and none of the three reported the generated blow bias. ${ }^{(13-15)}$ In addition, it is not known whether combining MCC with PEEP-ZEEP makes the maneuver more effective in terms of the flow bias generated.

The objective of the present study was to investigate the effects of MCC on the expiratory flow bias generated by the PEEP-ZEEP maneuver in patients on mechanical ventilation. Because the effects of MCC on PEF can be influenced by operator characteristics, such as hand size and hand grip strength, we compared compressions performed by three different respiratory therapists.

\section{METHODS}

This was a quantitative, experimental crossover study involving a convenience sample and conducted at the Hospital de Clínicas da Universidade Federal do Triângulo Mineiro, in the city of Uberaba, Brazil. The study was approved by the local research ethics committee (CAAE no. 47299815.8.0000.5154). Written informed consent was obtained from family members.

We included patients who had been on mechanical ventilation for more than $48 \mathrm{~h}$; were between 19 and 68 years of age; were hemodynamically stable-receiving low doses of vasoactive drugs or no vasoactive drugs and having a mean arterial pressure (MAP) $>60$ $\mathrm{mmHg}$; had adequate oxygenation $\left(\mathrm{FiO}_{2} \leq 0.4\right.$; PEEP $\leq 10 \mathrm{CmH}_{2} \mathrm{O}$; and $\mathrm{SpO}_{2}>90 \%$ ); and showed no signs of respiratory distress. The exclusion criteria were having intracranial hypertension, having pulmonary hypertension, being pregnant, having an undrained pneumothorax, having a rib fracture, and having a chest tube in place.

After being included, the patients were placed in the supine position, underwent the initial evaluation, and were submitted to endotracheal suctioning. The sensor of the $\mathrm{CO}_{2} \mathrm{SMO}$ Plus monitor (Dixtal Equipamentos Médicos, São Paulo, Brazil) was then connected, creating a link between the ventilator circuit and the endotracheal tube/tracheostomy tube, in order to obtain respiratory mechanics data.

Thirty minutes after endotracheal suctioning, we collected the baseline data and recorded ventilation for at least one minute, without changing the ventilator settings. The PEEP-ZEEP maneuver was then carried out in four distinct steps, the order in which they occurred being random and computer-generated. Of the 24 randomization possibilities, 12 were maintained so that the four possible steps were balanced in the first and fourth positions. The allocation was concealed until the patient was included in the study. The four steps were as follows: PEEP-ZEEP without MCC; PEEP-ZEEP with MCC applied by respiratory therapist 1 ; PEEP-ZEEP with MCC applied by respiratory therapist 2; and PEEP-ZEEP with MCC applied by respiratory therapist 3. Between each step, there was a 15-min interval, during which the patient was ventilated at the baseline settings. The three respiratory therapists who applied the maneuvers were part of the study research team and were female.

The PEEP-ZEEP maneuver was carried out during volume assist-control ventilation, with a tidal volume set to achieve a peak inspiratory pressure (PIP) of 30-35 $\mathrm{cmH}_{2} \mathrm{O}$, an inspiratory time of $1.0-1.5 \mathrm{~s}$, a square flow wave, and a PEEP of $15 \mathrm{cmH}_{2} \mathrm{O}$. At the beginning of the maneuver, PEEP was increased to $15 \mathrm{cmH}_{2} \mathrm{O}$, and, at the end of the inspiratory phase of the fifth cycle, PEEP was abruptly reduced to zero $\mathrm{cmH}_{2} \mathrm{O}-\mathrm{a}$ cycle called ZEEP. In each step, the maneuver was carried out twice, totaling ten cycles per step. Figure 1 illustrates the pressure curves and flow curves over time during the PEEP-ZEEP maneuver as applied in the study (two sequential maneuvers).

MCC was applied bilaterally on the lower third of the thorax, in an abrupt/rapid way (compression applied only at the start of expiration), and in synchrony with the reduction of PEEP to zero $\mathrm{CmH}_{2} \mathrm{O}$, which was achieved by observing the curves on the ventilator screen.

The patients were monitored continuously, and the maneuver was interrupted if the patients had an $\mathrm{SpO}_{2}$ $<90 \%$, a systolic blood pressure $<90 \mathrm{mmHg}$, an MAP $<60 \mathrm{mmHg}$, a heart rate $<60 \mathrm{bpm}$ or $>140$ bpm, or psychomotor agitation.

The maneuvers were continuously recorded by the device. Hemodynamic data (heart rate, systolic blood pressure, MAP, and diastolic blood pressure) and $\mathrm{SpO}_{2}$, as well as respiratory mechanics data, were recorded before the first step and $15 \mathrm{~min}$ after the end of the fourth step.

The size of the hands of the respiratory therapists who applied MCC was measured by the figure-of-eight method, ${ }^{(16)}$ and the maximum grip strength of the dominant hand was determined with a hydraulic dynamometer (JAMAR; Patterson Medical Co., Danbury, CT, USA). For determination of maximum hand grip strength, the respiratory therapists were placed in a sitting position, with the shoulders adducted, the 


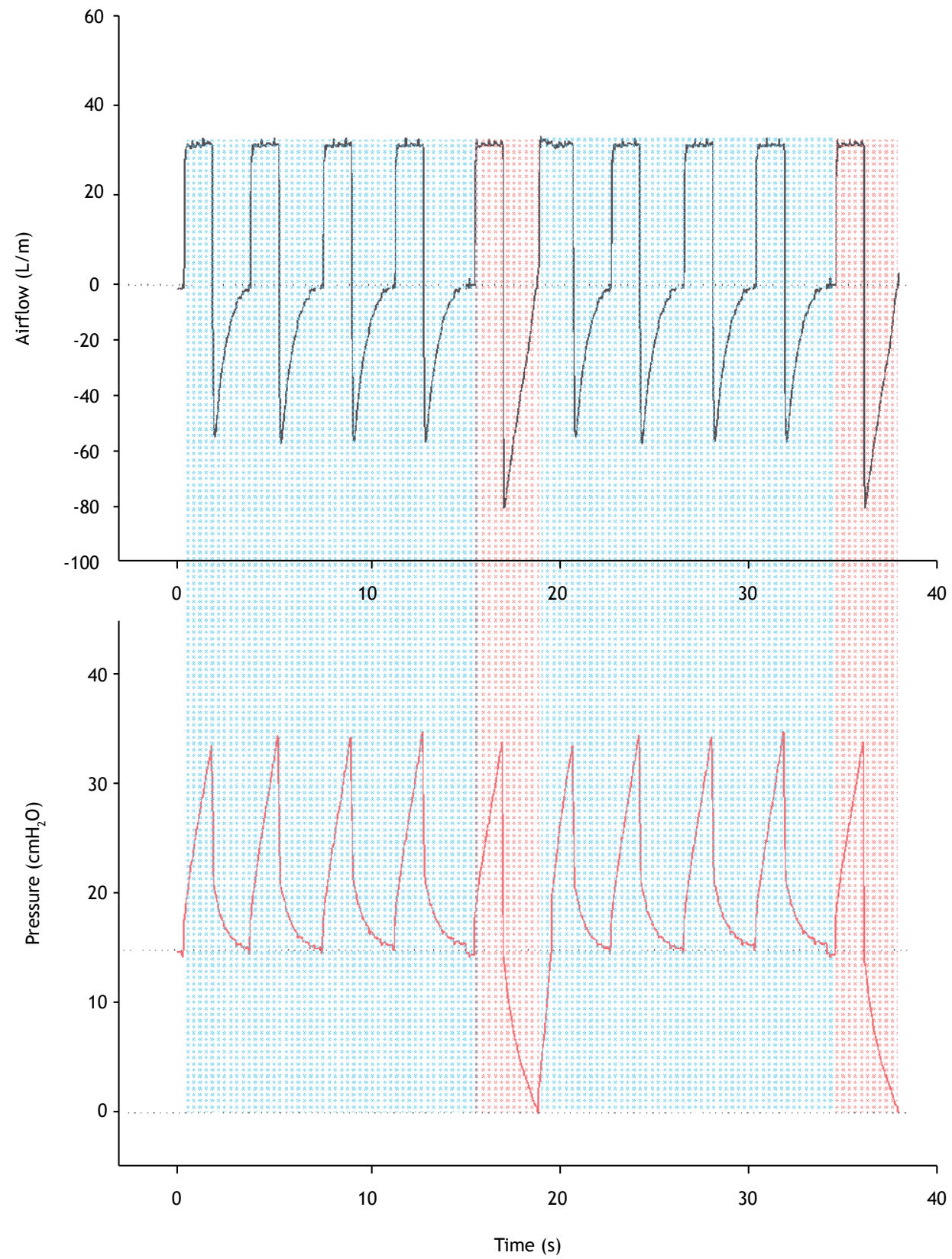

Figure 1. Flow curves (in black) and pressure curves (in red) during two sequential positive end-expiratory pressurezero end-expiratory pressure (PEEP-ZEEP) maneuvers during volume-controlled ventilation. After four cycles with PEEP set at $15 \mathrm{cmH}_{2} \mathrm{O}$ (shaded in blue), known as pre-ZEEP, there is a fifth cycle in which PEEP is abruptly reduced to zero $\mathrm{CmH}_{2} \mathrm{O}$ (shaded in red), known as ZEEP. Note the increase in peak expiratory flow during the ZEEP cycle as compared with the pre-ZEEP cycles.

elbow flexed at $90^{\circ}$, and the wrist/forearm in a neutral unsupported position, holding the dynamometer. ${ }^{(17)}$ Upon a verbal signal to start, the respiratory therapists gripped the dynamometer. Hand grip strength was measured three times, and the highest value obtained was used for analysis.

\section{Analysis of respiratory mechanics}

The system for acquisition of flow, pressure, and volume curves that was used was the $\mathrm{CO}_{2} \mathrm{SMO}$ Plus monitor (Dixtal Equipamentos Médicos) connected to a computer with the Analysis Plus software for Windows (Novametrix Medical Systems Inc., Wallingford, CT, USA), which records data at $100 \mathrm{~Hz}$ and allows subsequent analysis of the data stored. The analysis of the PEEP-ZEEP maneuver was divided into a pre-ZEEP cycle and a ZEEP cycle. Because the maneuver was applied twice in each step of the study, we selected and analyzed at least six cycles and two cycles, respectively, for the pre-ZEEP cycle and the 
ZEEP cycle, in order to obtain the mean values of PIP, inspiratory time, tidal volume, PEEP, PIF, and PEF for the pre-ZEEP cycle and for the ZEEP cycle. The analysis of the pre-ZEEP cycle was performed only during the PEEP-ZEEP maneuver without MCC. For the analysis of respiratory mechanics at baseline and at the end of the fourth step, we randomly selected at least 10 cycles and calculated the mean values of the variables of interest.

The primary outcome was the influence of MCC on the expiratory flow bias (as assessed by PEF - PIF difference) generated by the PEEP-ZEEP maneuver.

\section{Statistical analysis}

Data were presented as mean and standard deviation or as absolute and relative values. Comparative analyses of respiratory mechanics variables for the ZEEP cycle vs. the pre-ZEEP cycle (of the PEEP-ZEEP maneuver without $\mathrm{MCC}$ ), as well as of respiratory mechanics and hemodynamic variables at baseline vs. at the end of the study, were carried out with the paired t-test. We analyzed the influence of MCC with repeated-measures ANOVA, testing four within-factor levels (without MCC, MCC-1, MCC-2, and MCC-3; the last three reflecting the performance of the three different respiratory therapists, respectively). Subsequently, a simple contrast (with Bonferroni correction) was used to determine whether MCC performed by any of the three respiratory therapists was significantly more efficient than was the "without MCC" condition.

Although the study was not designed to explore the influence of respiratory therapist characteristics on the final performance (i.e., accelerate expiratory flow), we conducted an exploratory analysis using within-patient linear regression (having adjusted for PEF without MCC in each patient), in which the following variables were tested as independent variables: maximum hand grip strength; and hand circumference. Values of $p<0.05$ were considered statistically significant. The statistical analysis was performed with the SPSS Statistics software package, version 20.0 for Windows (IBM Corporation, Armonk, NY, USA).

\section{RESULTS}

Twelve patients were included in the study. However, 2 of those 12 were excluded: one for experiencing an increased respiratory rate and respiratory distress during the protocol; and the other because of failures during acquisition of respiratory mechanics data. The characteristics of the 10 patients who participated in the study are described in Table 1.

Figure 2 shows the PEEP-ZEEP maneuver without MCC (in A) and the PEEP-ZEEP maneuver with MCC applied by respiratory therapist 2 (in B) in a patient who is representative of the study sample. The differences between the PEF values generated during the ZEEP cycle illustrate the contribution of the PEEP-ZEEP maneuver and of MCC to the occurrence of an expiratory flow bias.
Table 1. Baseline characteristics of the patients included in the study $(\mathrm{N}=10){ }^{\mathrm{a}}$

\begin{tabular}{lc}
\multicolumn{1}{c}{ Characteristic } & Result \\
Age, years & $63 \pm 14$ \\
Male gender & $6(60.0)$ \\
Diagnosis & \\
$\quad$ Acute respiratory failure & $1(10.0)$ \\
$\quad$ Stroke & $1(10.0)$ \\
Traumatic brain injury & $1(10.0)$ \\
$\quad$ Decreased level of consciousness & $2(20.0)$ \\
Cardiopulmonary arrest & $5(50.0)$ \\
Level of consciousness or sedation & \\
$\quad$ Richmond Agitation Sedation Scale & \\
Glasgow Coma Scale & $-5(100.0)$ \\
Duration of ventilation, days & $9 \pm 3$ \\
Ventilator settings & $16 \pm 7$ \\
Ventilation mode & \\
$\quad$ Pressure-controlled & \\
$\quad$ Pressure support & $6(60.0)$ \\
Positive end-expiratory pressure, & $4(40.0)$ \\
$\mathrm{CmH}_{2} \mathrm{O}$ & $7.7 \pm 0.9$ \\
FiO $_{2}$ & \\
Respiratory rate, breaths/min $^{\mathrm{b}}$ & $0.34 \pm 0.08$ \\
\hline
\end{tabular}

${ }^{a}$ Values expressed as $\mathrm{n}(\%)$ or as mean \pm SD. ${ }^{\text {bScale }}$ used in 1 patient. cScale used in 9 patients.

Table 2 shows respiratory mechanics variables for the pre-ZEEP and ZEEP cycles of the PEEP-ZEEP maneuver without MCC and for the ZEEP cycle of the PEEP-ZEEP maneuver with MCC applied by each of the three respiratory therapists in the study. $A$ comparison between the pre-ZEEP and ZEEP cycles demonstrates that the abrupt reduction of PEEP to zero $\mathrm{CmH}_{2} \mathrm{O}$ increased PEF by $29.4 \pm 9.4 \mathrm{~L} / \mathrm{min}$, resulting in a significant increase in the PEF/PIF ratio and in PEF - PIF difference (Table 2). With regard to the other variables, only PIP was higher in the ZEEP cycle than in the pre-ZEEP cycle (1.4 $\pm 1.4 \mathrm{cmH}_{2} \mathrm{O}$ higher), and, as expected, PEEP was lower (and close to zero) in the ZEEP cycle as compared with the pre-ZEEP cycle.

MCC, regardless of the respiratory therapist who performed it, resulted in a significant increase in PEF $(p<0.001)$ and in the expiratory flow bias, as expressed either by the PEF/PIF ratio $(p=0.004)$ or by PEF - PIF difference ( $p<0.001$; Figure 3 ). The increase caused by MCC was, on average, $7.2 \pm 3.3$ $\mathrm{L} / \mathrm{min}, 6.7 \pm 3.4 \mathrm{~L} / \mathrm{min}$, and $0.3 \pm 0.2 \mathrm{~L} / \mathrm{min}$ for PEF, PEF - PIF difference, and the PEF/PIF ratio, respectively. In Table 2, we can see that the increase provided by MCC in the expiratory flow bias occurred because of the increase in PEF generated by the compression, given that no significant difference was found across the PIFs generated during the four steps of the study.

Considering PEF - PIF difference > $33 \mathrm{~L} / \mathrm{min}$ as the threshold that is most appropriate to represent the target expiratory flow bias during therapy for secretion clearance, we found that, of the 40 maneuvers performed, only $1(2,5 \%)$, which was applied by 
(A)

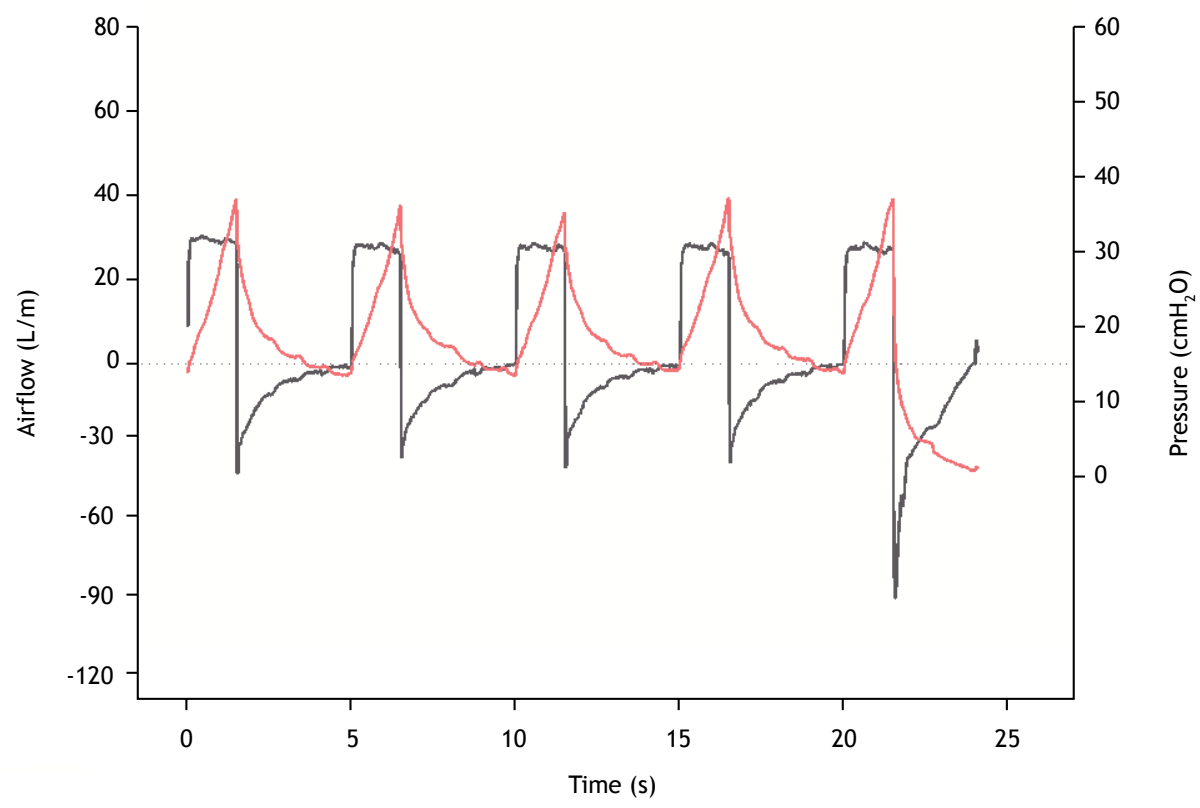

(B)

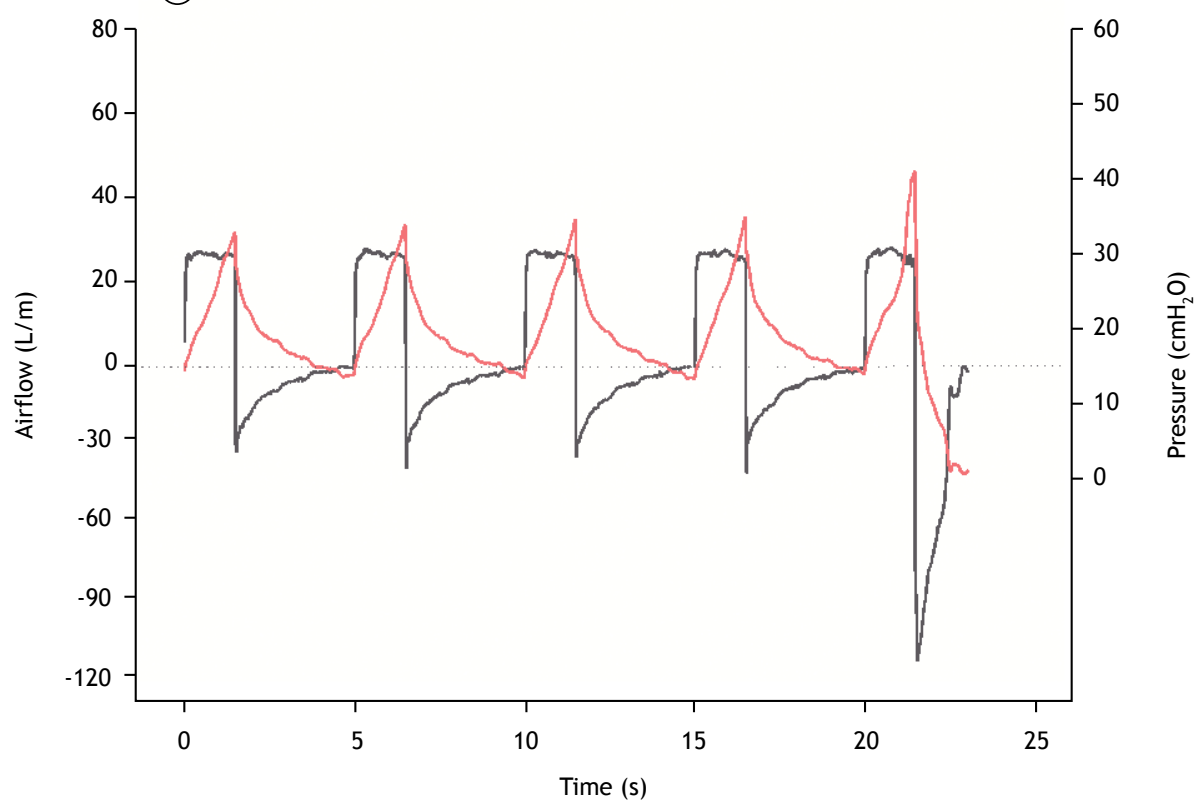

Figure 2. Positive end-expiratory pressure-zero end-expiratory pressure (PEEP-ZEEP) maneuver without manual chest compression (in A) and PEEP-ZEEP maneuver with manual chest compression applied by respiratory therapist 2 (in B) in a patient who is representative of the study sample. The expiratory flow bias generated during the ZEEP cycle without manual chest compression (in $\mathrm{A}$ ) was $\approx 60 \mathrm{~L} / \mathrm{min}$, whereas, with the addition of manual chest compression (in $\mathrm{B}$ ), the expiratory flow bias was $\approx 83 \mathrm{~L} / \mathrm{min}$.

respiratory therapist 3, did not reach the threshold necessary to move secretion toward the glottis.

Applying MCC in combination with the PEEP-ZEEP maneuver resulted in higher PIP as compared with applying the PEEP-ZEEP maneuver without MCC. Bonferroni analysis revealed that this difference was caused by the MCC applied by respiratory therapist 3 (Table 2, Figure 4). However, the mean PIP during MCC was below $40 \mathrm{cmH}_{2} \mathrm{O}$, and the PIP was between 40.0 and $45.5 \mathrm{cmH}_{2} \mathrm{O}$ in only 4 of the 30 cycles (Figure 4).

With the exception of dynamic compliance of the respiratory system, which showed an increase when 

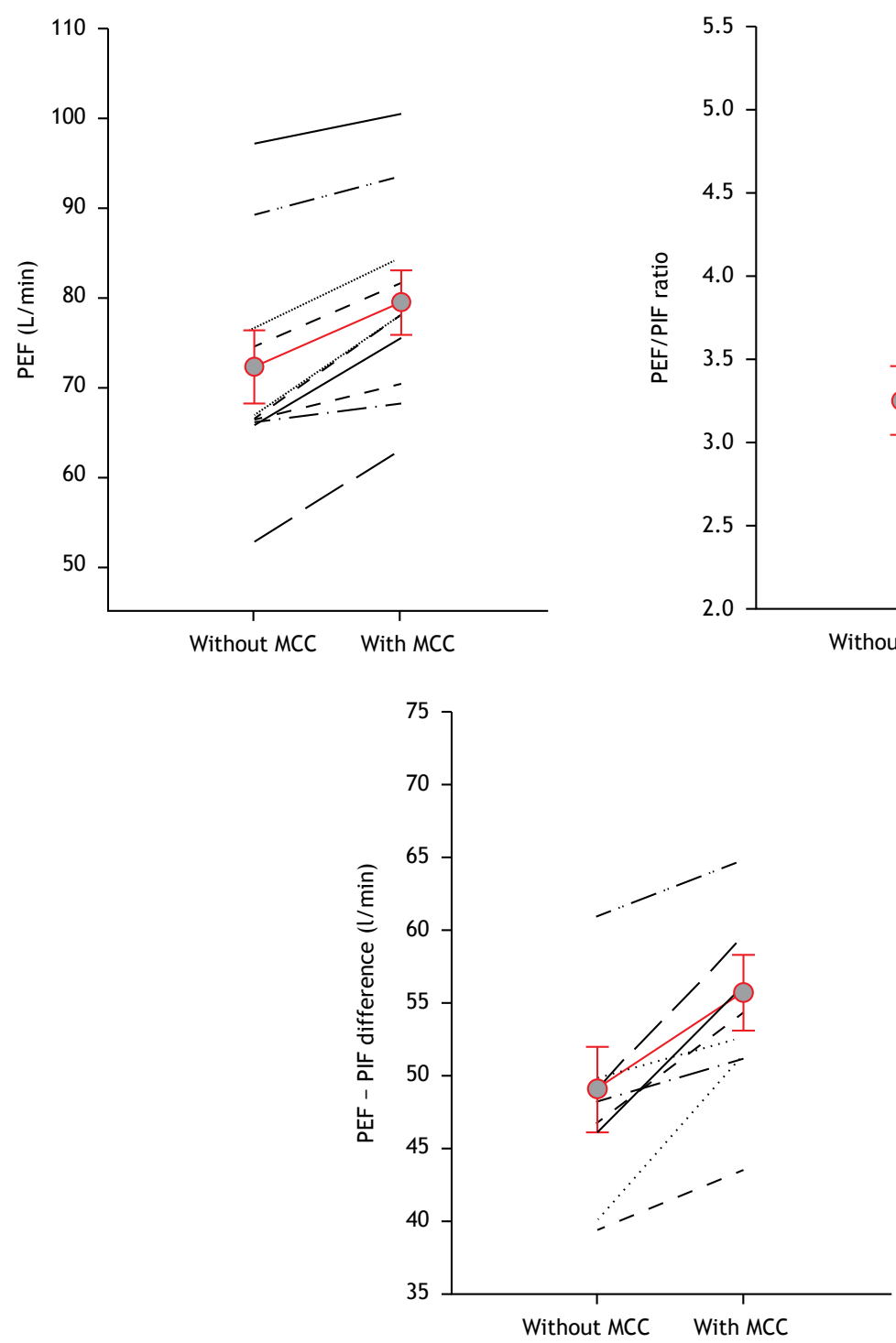

Figure 3. Peak expiratory flow (PEF), PEF/peak inspiratory flow (PIF) ratio, and PEF - PIF difference generated during the positive end-expiratory pressure-zero end-expiratory pressure (PEEP-ZEEP) maneuver without manual chest compression (MCC) and during the PEEP-ZEEP maneuver with MCC. The values presented for "with MCC" are the means generated by the three respiratory therapists. The black lines illustrate the values reached in each patient in the study, and the red lines represent the means \pm standard error.

baseline and end-of-study values were compared, all respiratory mechanics variables and hemodynamic parameters, as well as $\mathrm{SpO}_{2}$, showed no differences, which demonstrates that the application of the maneuvers was safe in respiratory and hemodynamic terms (Table 1A; JBP online appendix - http:// jornaldepneumologia.com.br/detalhe_anexo. asp?id=57).

The values for hand circumference and maximum hand grip strength, respectively, for each respiratory therapist were as follows: $37.5 \mathrm{~cm}$ and $25.3 \mathrm{kgf}$, for respiratory therapist $1 ; 41.0 \mathrm{~cm}$ and $28.6 \mathrm{kgf}$, for respiratory therapist 2 ; and $45.0 \mathrm{~cm}$ and $17.0 \mathrm{kgf}$, for respiratory therapist 3 . The partial regression coefficients for maximum hand grip strength vs.

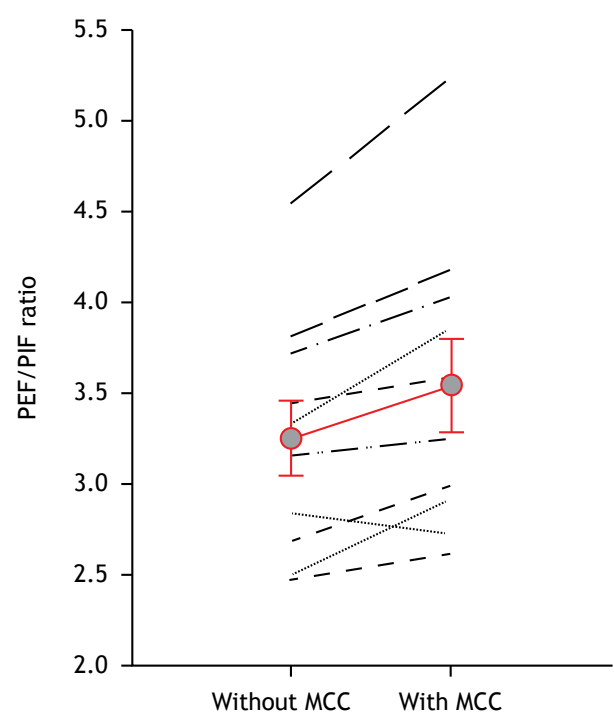

PEF and PEF - PIF difference were 0.36 and 0.46 , respectively; whereas the partial regression coefficients for hand circumference vs. PEF and PEF - PIF difference were -0.21 and -0.33 , respectively. These results indicate that hand grip strength is a better candidate (positive correlation) to explain the significant difference in performance among respiratory therapists, whereas hand size has a spurious negative correlation.

\section{DISCUSSION}

The major finding of the present study is that MCC potentiated the increase in the expiratory flow bias generated by the PEEP-ZEEP maneuver, making the maneuver potentially more effective in terms of 
Table 2. Respiratory mechanics variables for the cycle prior to zero end-expiratory pressure and the zero end-expiratory pressure cycle of the positive end-expiratory pressure-zero end-expiratory pressure maneuver without manual chest compression and for the zero end-expiratory pressure cycle of the positive end-expiratory pressure-zero end-expiratory pressure maneuver with manual chest compression.

\begin{tabular}{|c|c|c|c|c|c|c|c|}
\hline \multirow[t]{3}{*}{ Variable } & \multicolumn{2}{|c|}{ PEEP-ZEEP without MCC } & \multirow[t]{3}{*}{$p^{*}$} & \multirow{2}{*}{\multicolumn{3}{|c|}{$\begin{array}{l}\text { PEEP-ZEEP with MCC } \\
\text { ZEEP with MCC }\end{array}$}} & \multirow[t]{3}{*}{$\mathbf{p}^{\dagger}$} \\
\hline & \multirow[t]{2}{*}{ Pre-ZEEP } & \multirow[t]{2}{*}{ ZEEP } & & & & & \\
\hline & & & & RT 1 & RT 2 & RT 3 & \\
\hline $\mathrm{V}_{\mathrm{T}}, \mathrm{mL}$ & $556 \pm 167$ & $519 \pm 173$ & 0.145 & $524 \pm 154$ & $532 \pm 144$ & $529 \pm 153$ & 0.684 \\
\hline $\mathrm{PIP}, \mathrm{cmH}_{2} \mathrm{O}$ & $31.5 \pm 3.4$ & $32.9 \pm 2.9$ & 0.011 & $34.7 \pm 4.3$ & $36.6 \pm 4.3$ & $38.2 \pm 3.8^{\varsigma}$ & 0.008 \\
\hline PEEP, $\mathrm{cmH}_{2} \mathrm{O}$ & $13.1 \pm 4.7$ & $1.9 \pm 0.8$ & $<0.001$ & $1.7 \pm 1.1$ & $1.3 \pm 0.9$ & $1.9 \pm 1.8$ & 0.552 \\
\hline$T_{\text {INSP }}, s$ & $1.6 \pm 0.1$ & $1.5 \pm 0.1$ & 0.065 & $1.5 \pm 0.0$ & $1.5 \pm 0.0$ & $1.5 \pm 0.1$ & 0.632 \\
\hline $\mathrm{PIF}, \mathrm{L} / \mathrm{min}$ & $23.4 \pm 6.2$ & $23.1 \pm 6.0$ & 0.071 & $23.0 \pm 6.2$ & $23.5 \pm 5.7$ & $24.5 \pm 7.8$ & 0.331 \\
\hline PEF, L/min & $42.8 \pm 14.0$ & $72.2 \pm 12.9$ & $<0.001$ & $79.6 \pm 12.3^{\ddagger}$ & $82.0 \pm 13.1^{\S}$ & $76.8 \pm 12.8$ & 0.043 \\
\hline PEF/PIF ratio & $1.9 \pm 0.5$ & $3.3 \pm 0.7$ & $<0.001$ & $3.6 \pm 0.7^{\prime 1}$ & $3.6 \pm 0.8^{\Uparrow}$ & $3.4 \pm 1.0$ & 0.019 \\
\hline $\begin{array}{l}\text { PEF - PIF } \\
\text { difference, L/min }\end{array}$ & $19.4 \pm 12.0$ & $49.1 \pm 9.4$ & $<0.001$ & $56.6 \pm 7.9^{* *}$ & $58.4 \pm 9.7^{\S}$ & $52.3 \pm 11.2$ & 0.028 \\
\hline
\end{tabular}

PEEP: positive end-expiratory pressure; ZEEP: zero end-expiratory pressure; MCC: manual chest compression; $\mathrm{RT}$ : respiratory therapist; $\mathrm{V}_{\mathrm{T}}$ : tidal volume; PIP: peak inspiratory pressure; $\mathrm{T}_{\text {INSP }}$ : inspiratory time; and PIF: peak inspiratory flow; and PEF: peak expiratory flow. *Comparison between pre-ZEEP and ZEEP (paired t-test). ${ }^{+}$Comparison among the four ZEEP cycles (repeated-measures ANOVA). ${ }^{\ddagger} p=0.007 ;{ }^{\S} p=0.001 ; " 1 p=0.002 ;{ }^{9} p=$ $0.011 ; * * p=0.003$. Comparisons between ZEEP without MCC and ZEEP with MCC (Bonferroni correction).

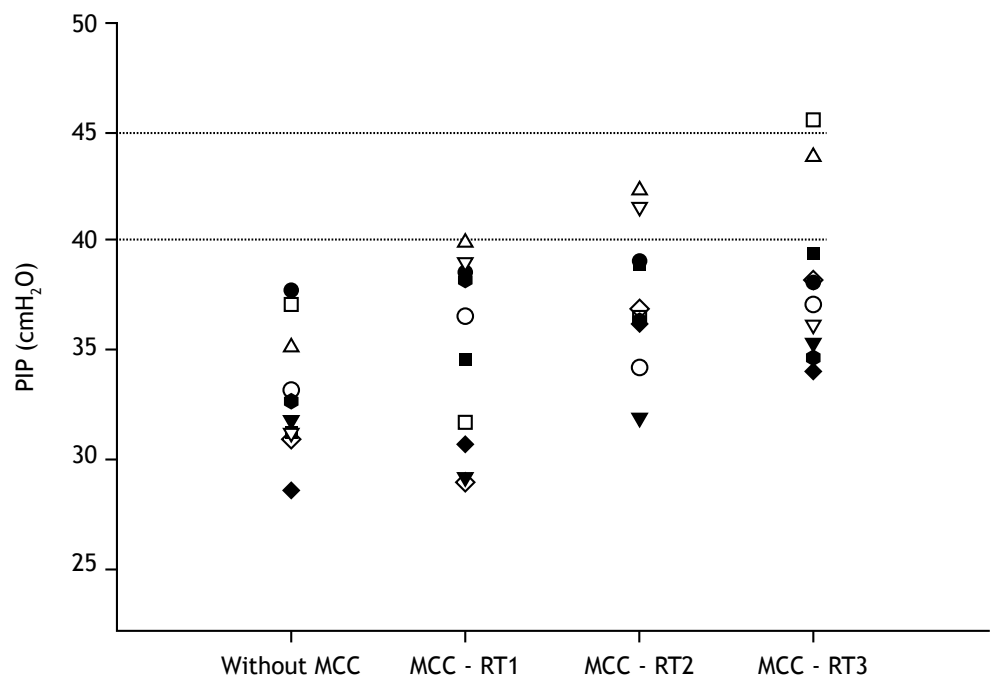

Figure 4. Peak inspiratory pressures (PIPs) generated during the positive end-expiratory pressure-zero end-expiratory pressure (PEEP-ZEEP) maneuver without manual chest compression (MCC) and during the PEEP-ZEEP maneuver with MCC applied by each of the three respiratory therapists (RT1, RT2, and RT3) who participated in the study. The straight lines mark safe threshold PIP values.

pulmonary secretion removal in patients on mechanical ventilation. However, whereas MCC was responsible for increasing the expiratory flow bias by $7 \mathrm{~L} / \mathrm{min}$, the contribution of the PEEP-ZEEP maneuver-performed during volume-controlled ventilation-was $49 \mathrm{~L} / \mathrm{min}$, which is highly significant and well above the threshold considered necessary for pulmonary secretion clearance (PEF - PIF difference > $33 \mathrm{~L} / \mathrm{min}$ ).

MCC is commonly applied in one of two different ways $^{(18)}$ : slowly and gradually throughout the expiratory phase; or abruptly and rapidly only at the start of expiration. In the present study, we chose the latter because it has been shown to be hemodynamically safe and more effective both in terms of an increase in PEF and in terms of secretion clearance, as compared with the former, in animal studies ${ }^{(18)}$ and in studies of mechanical models. ${ }^{(19)}$

Comparison across studies in the literature examining the effects of MCC requires caution. In addition to there being two distinct MCC modalities, some studies have been conducted in spontaneously breathing individuals ${ }^{(20,21)}$; others have compared MCC and vibration (which has an oscillatory component that seems to potentiate the increase in PEF) ${ }^{(20,22)}$; others have finished MCC with rapid decompression of the chest, ${ }^{(23)}$ which can reduce airway pressure and increase PIF when ventilation modes in which inspiratory flow is free, such as pressure-control ventilation, are used; and others have not described the maneuver in detail, ${ }^{(23)}$ which makes it difficult to interpret their findings. Among the studies investigating the use of abrupt MCC 
during mechanical ventilation are studies of mechanical models, animal models, adults, and children; those studies reported that PEF increased significantly by 8.8 $\mathrm{L} / \mathrm{min}_{\text {, }^{(19)}} 8.9 \mathrm{~L} / \mathrm{min}^{(18)} 16.2$ to $43.8 \mathrm{~L} / \mathrm{min}^{(23-25)}$ and $13.8 \%,{ }^{(26)}$ respectively. The increase in PEF caused by MCC in our study was smaller than that found in studies of adults. Such differences are probably explained by the physical characteristics of the MCC operator and mainly by the force applied to the chest and the properties of the respiratory system of the patients studied. In the present study, we found that the grip strength of the dominant hand correlated weakly with the PEF generated during MCC and moderately with the PEF - PIF difference generated during MCC. However, it is noteworthy that the study design, with a small number of respiratory therapists, was not appropriate to establish correlations among the study variables. Wong et al.(27) assessed the effects of vibration (without MCC), percussion, and shaking applied by ten respiratory therapists in an animal model, during mechanical ventilation, and also found no correlation between the size of the hands of the respiratory therapists and the resulting force during the application of these techniques.

The higher PIP generated by respiratory therapist 3 may have been due to poorer synchronization between the application of MCC and the start of expiration. Earlier application of MCC, before the expiratory valve starts to open, translates to a greater increase in PIP. However, the mean PIP generated during the MCC applied by the three respiratory therapists was below $40 \mathrm{cmH}_{2} \mathrm{O}$, and in only $13 \%$ of the cycles did PIP reach values ranging from 40.0 to $45.5 \mathrm{cmH}_{2} \mathrm{O}$, which is still considered a safe threshold. ${ }^{(28,29)}$ In addition, the increase in PIP occurred because of momentarily decreased rib cage compliance or of increased pleural pressure caused by the compression maneuver and therefore did not increase the transpulmonary pressure. ${ }^{(30)}$ It is very likely that the physiological consequences of the compression maneuver are equivalent to the changes observed in spontaneous cough, or even in trumpet players: despite the large momentary increase in intra-alveolar pressure, there is a concomitant increase in pleural pressures, without there being an increase in the transpulmonary pressure gradient and therefore without risk of damage to the lung parenchyma. ${ }^{(31)}$ Most studies on MCC have not described its effects on the expiratory flow bias. ${ }^{(24,25,32-34)}$ An exception is the study conducted by Gregson et al., (26) who showed that only when combined with MCC did the manual hyperinflation maneuver result in a PEF/PIF ratio $>1.1$. One possible explanation for studies that failed to demonstrate that the use of MCC results in enhanced secretion removal ${ }^{(32,34)}$ is that MCC was used with the specific objective of increasing PEF and there was no awareness of the need to increase the expiratory flow bias. Higher tidal volumes or higher inspiratory pressures are often associated with MCC. These settings can generate high PIFs, which neutralize the PEF increase caused by MCC, making the maneuver only slightly effective or completely ineffective.

The present study has some limitations, such as the small number of patients. However, physiological studies that aim to describe respiratory patterns usually have smaller samples, with 10 to 14 patients. ${ }^{(35,36)}$ A second limitation is that both the PEEP-ZEEP maneuver and MCC can cause peripheral airway closure and expiratory flow limitation, conditions that were not investigated in our study, and therefore prudence is required in applying MCC in patients who are susceptible to these conditions. ${ }^{(23)}$ Finally, the thresholds described for an expiratory flow bias to move secretion toward the glottis have not yet been investigated in humans and should be interpreted with caution. It is of note that the thresholds found in the study by Li Bassi et al.,(12) PEF - PIF difference $>33 \mathrm{~L} / \mathrm{min}$ and PEF/PIF ratio > 4.3 , were obtained in sedated animals on controlled mechanical ventilation, which makes it difficult to use those thresholds in patients on assisted spontaneous ventilation, as is the case of most of the patients in our study. It is also of note that the properties of the secretion of those animals were not analyzed, and secretion viscosity certainly influences the thresholds obtained. In addition, it is not known whether there is a positive linear relationship between the flow bias and secretion removal, that is, whether a greater flow bias (above a certain threshold) translates to greater secretion movement toward the glottis. Therefore, in clinical practice, combining MCC with the PEEP-ZEEP maneuver should not be discouraged solely on the basis of our results.

The results of our study support that the PEEP-ZEEP maneuver, alone or in combination with $M C C$, is a promising technique for secretion removal; however, the level of evidence remains low. Further studies are needed that use a standardized PEEP-ZEEP maneuver-carried out during volume-controlled ventilation and resulting in a PEF - PIF difference $>33 \mathrm{~L} / \mathrm{min}$-and that explore outcomes related to possible adverse effects, such as induction of lung collapse, and outcomes measuring the effectiveness of the maneuver, such as the quantity of secretions removed.

\section{REFERENCES}

1. Branson RD. Secretion management in the mechanically ventilated patient. Respir Care. 2007;52(10): 1328-42; discussion 1342-7.

2. Sackner MA, Hirsch J, Epstein S. Effect of cuffed endotracheal tubes on tracheal mucous velocity. Chest. 1975;68(6):774-7. https://doi org/10.1378/chest.68.6.774

3. Li Bassi G, Zanella A, Cressoni M, Stylianou M, Kolobow T. Following tracheal intubation, mucus flow is reversed in the semirecumbent position: possible role in the pathogenesis of ventilator-associated pneumonia. Crit Care Med. 2008;36(2):518-25. https://doi. org/10.1097/01.CCM.0000299741.32078.E9

4. Konrad F, Schreiber T, Brecht-Kraus D, Georgieff M. Mucociliary transport in ICU patients. Chest. 1994;105(1):237-41. https://doi. org/10.1378/chest.105.1.237

5. Epstein SK. Weaning from ventilatory support. Curr Opin Crit Care. 
2009;15(1):36-43. https://doi.org/10.1097/MCC.0b013e3283220e07

6. Gosselink R, Bott J, Johnson M, Dean E, Nava S, Norrenberg $M$, et al. Physiotherapy for adult patients with critical illness: recommendations of the European Respiratory Society and European Society of Intensive Care Medicine Task Force on Physiotherapy for Critically III Patients. Intensive Care Med. 2008;34(7):1188-99. https:// doi.org/10.1007/s00134-008-1026-7

7. França EÉ, Ferrari F, Fernandes P, Cavalcanti R, Duarte A, Martinez BP, et al. Physical therapy in critically ill adult patients: recommendations from the Brazilian Association of Intensive Care Medicine Department of Physical Therapy. Rev Bras Ter Intensiva. 2012;24(1):6-22. https:// doi.org/10.1590/S0103-507X2012000100003

8. Kim CS, Iglesias AJ, Sackner MA. Mucus clearance by two-phase gas-liquid flow mechanism: asymmetric periodic flow model. J Appl Physiol (1985). 1987;62(3):959-71. https://doi.org/10.1152/ jappl.1987.62.3.959

9. Benjamin RG, Chapman GA, Kim CS, Sackner MA. Removal of bronchial secretions by two-phase gas-liquid transport. Chest. 1989;95(3):658-63. https://doi.org/10.1378/chest.95.3.658

10. Freitag L, Long WM, Kim CS, Wanner A. Removal of excessive bronchial secretions by asymmetric high-frequency oscillations. J Appl Physiol (1985). 1989;67(2):614-9. https://doi.org/10.1152/ jappl.1989.67.2.614

11. Volpe MS, Adams $A B$, Amato $M B$, Marini JJ. Ventilation patterns influence airway secretion movement. Respir Care. 2008;53(10):1287-94.

12. Li Bassi G, Saucedo L, Marti JD, Rigol M, Esperatti M, Luque $N$, et al. Effects of duty cycle and positive end-expiratory pressure on mucus clearance during mechanical ventilation* Crit Care Med. 2012;40(3):895-902. https://doi.org/10.1097/ CCM.0b013e318236efb5

13. Herbst-Rodrigues MV, Carvalho VO, Auler JO Jr, Feltrim MI. PEEP-ZEEP technique: cardiorespiratory repercussions in mechanically ventilated patients submitted to a coronary artery bypass graft surgery. J Cardiothorac Surg. 2011;6:108. https://doi. org/10.1186/1749-8090-6-108

14. Santos FR, Schneider Júnior LC, Forgiarini Junior LA, Veronezi $\mathrm{J}$. Effects of manual rib-cage compression versus PEEP-ZEEP maneuver on respiratory system compliance and oxygenation in patients receiving mechanical ventilation. Rev Bras Ter Intensiva. 2009;21(2):155-61. https://doi.org/10.1590/S0103$507 \times 2009000200007$

15. Lobo DM, Cavalcante LA, Mont'Alverne DG. Applicability of bag squeezing and zeep maneuvers in mechanically ventilated patients. Rev Bras Ter Intensiva. 2010;22(2):186-91. https://doi.org/10.1590/ S0103-507X2010000200013

16. Pellecchia GL. Figure-of-eight method of measuring hand size: reliability and concurrent validity. J Hand Ther. 2003:16(4):300-4. https://doi.org/10.1197/S0894-1130(03)00154-6

17. Dias JA, Ovando AC, Külkamp W, Borges Junior NG. Hand grip strength: evaluation methods and factors influencing this measure. Rev Bras Cineantropom Desempenho Hum. 2010;12(3):209-16.

18. Marti JD, Li Bassi G, Rigol M, Saucedo L, Ranzani OT, Esperatti M, et al. Effects of manual rib cage compressions on expiratory flow and mucus clearance during mechanical ventilation. Critical Care Med. 2013:41(3):850-6. https://doi.org/10.1097/CCM.0b013e3182711b52

19. Shannon H, Stiger R, Gregson RK, Stocks J, Main E. Effect of chest wall vibration timing on peak expiratory flow and inspiratory pressure in a mechanically ventilated lung model. Physiotherapy. 2010;96(4):344-9. https://doi.org/10.1016/..physio.2010.02.007

20. McCarren B, Alison JA, Herbert RD. Vibration and its effect on the respiratory system. Aust J Physiother. 2006;52(1):39-43. https://doi. org/10.1016/S0004-9514(06)70060-5

21. Nozoe M, Mase K, Ogino T, Murakami S, Takashima S, Domen K. Effects of chest wall compression on expiratory flow rates in patients with chronic obstructive pulmonary disease. Braz J Phys Ther 2016;20(2):158-65. https://doi.org/10.1590/bjpt-rbf.2014.0145

22. McCarren B, Alison JA, Herbert RD. Manual vibration increases expiratory flow rate via increased intrapleural pressure in healthy adults: an experimental study. Aust J Physiother. 2006;52(4):267-71. https://doi.org/10.1016/S0004-9514(06)70006-X

23. Guimarães FS, Lopes AJ, Constantino SS, Lima JC, Canuto P, de Menezes SL. Expiratory rib cage Compression in mechanically ventilated subjects: a randomized crossover trial [corrected]. Respiratory Care. 2014;59(5):678-85. Erratum in Respir Care. 2014;59(7):e107.

24. MacLean D, Drummond G, Macpherson C, McLaren G, Prescott R. Maximum expiratory airflow during chest physiotherapy on ventilated patients before and after the application of an abdominal binder. Intensive Care Med. 1989;15(6):396-9. https://doi.org/10.1007/ BF00261500

25. Silva AR, Fluhr $S A$, Bezerra Ade L, Correia Júnior MA, França $E E$, Andrade FM. Expiratory peak flow and respiratory system resistance in mechanically ventilated patients undergoing two different forms of manually assisted cough. Rev Bras Ter Intensiva. 2012;24(1):58-63. https://doi.org/10.1590/S0103-507X2012000100009

26. Gregson RK, Shannon H, Stocks J, Cole TJ, Peters MJ, Main E. The unique contribution of manual chest compression-vibrations to airflow during physiotherapy in sedated, fully ventilated children Pediatr Crit Care Med. 2012;13(2):e97-e102. https://doi.org/10.1097/ PCC.0b013e3182230f5a

27. Wong WP, Paratz JD, Wilson K, Burns YR. Hemodynamic and ventilatory effects of manual respiratory physiotherapy techniques of chest clapping, vibration, and shaking in an animal model. $J$ Appl Physiol (1985). 2003:95(3):991-8. https://doi.org/10.1152/ japplphysiol.00249.2003

28. Skinner EH, Pearce A Sturgess T. Development of a Performance Standard and Assessment Tool for Ventilator Hyperinflation Competency. J Pulm Respir Med. 2015;5(1):1000237. https://doi. org/10.4172/2161-105X.1000237

29. Boussarsar M, Thierry G, Jaber S, Roudot-Thoraval F, Lemaire $F$, Brochard L. Relationship between ventilatory settings and barotrauma in the acute respiratory distress syndrome. Intensive Care Med. 2002;28(4):406-13. https://doi.org/10.1007/s00134-0011178-1

30. Dreyfuss D, Soler P, Basset G, Saumon G. High inflation pressure pulmonary edema. Respective effects of high airway pressure, high tidal volume, and positive end-expiratory pressure. Am Rev Respir Dis. 1988:137(5):1159-64. https://doi.org/10.1164/ajrccm/137.5.1159

31. Slutsky AS, Ranieri VM. Ventilator-induced lung injury. N Engl J Med. 2013;369(22):2126-36. https://doi.org/10.1056/NEJMra1208707

32. Genc AA, Akan M, Gunerli A. The effects of manual hyperinflation with or without rib-cage compression in mechanically ventilated patients. It J Physiother. 2011;1:48-54

33. Yousefnia-Darzi F, Hasavari F, Khaleghdoost T, Kazemnezhad-Leyli E, Khalili M. Effects of thoracic squeezing on airway secretion removal in mechanically ventilated patients. Iran J Nurs Midwifery Res. 2016;21(3):337-42. https://doi.org/10.4103/1735-9066.180374

34. Unoki T, Kawasaki $Y$, Mizutani T, Fujino $Y$, Yanagisawa $Y$, Ishimatsu $\mathrm{S}$, et al. Effects of expiratory rib-cage compression on oxygenation, ventilation, and airway-secretion removal in patients receiving mechanical ventilation. Respir Care. 2005;50(11):1430-7.

35. Borges JB, Okamoto VN, Matos GF, Caramez MP, Arantes PR, Barros $F$, et al. Reversibility of lung collapse and hypoxemia in early acute respiratory distress syndrome. Am J Respir Crit Care Med. 2006;174(3):268-78. https://doi.org/10.1164/rccm.200506-9760C

36. Pelosi $P$, Cadringher $P$, Bottino $N$, Panigada $M$, Carrieri $F$, Riva $E$, et al. Sigh in acute respiratory distress syndrome. Am J Respir Crit Care Med. 1999;159(3):872-80. https://doi.org/10.1164/ ajrccm.159.3.9802090 